Brazilian Journal

of Chemical

\title{
MATHEMATICAL MODELING OF CAPSULAR POLYSACCHARIDE PRODUCTION BY Neisseria meningitidis SEROGROUP C IN BIOREACTORS
}

\author{
A. W. S. Henriques ${ }^{1}$, E. Jessouroun ${ }^{2}$, E. L. Lima ${ }^{3}$ and T. L. M. Alves ${ }^{3}$ \\ ${ }^{1}$ Faculdade de Farmácia. Subreitoria de Ciências da Saúde, Universidade Estácio de Sá, \\ Rua do Bispo 83, CEP 20261-060, Rio de Janeiro - RJ, Brasil, \\ ${ }^{2}$ Instituto de Tecnologia em Imunobiológicos, Bio Manguinhos, FIOCRUZ, \\ Av. Brasil 4365, CEP 21045-900, Rio de Janeiro - RJ, Brasil \\ ${ }^{3}$ Programa de Engenharia Química, COPPE/UFRJ, \\ Cx. P. 68502, CEP 21945-970, Rio de Janeiro - RJ, Brasil \\ E-mail: awshenriques@globo.com
}

(Received: October 24, 2004 : Accepted: July 7, 2005)

\begin{abstract}
In this work, the process of capsular polysaccharide production by Neisseria meningitidis serogroup $\mathrm{C}$ was studied. Batch experimental runs were conducted in a set of one-liter bioreactors with $0.5 \mathrm{~L}$ of Frantz cultivation medium. Cultivation temperature and $\mathrm{pH}$ were controlled at optimal pre-established values. The dynamic behavior of the bacteria was analyzed based on biomass growth, glucose uptake, polysaccharide production and dissolved oxygen time profile obtained in a set of experimental runs with initial concentrations of glucose that varied from 5 to $13.5 \mathrm{~g} / \mathrm{L}$. Formulated hypotheses were then employed in the construction of a phenomenological model of the bioprocess under study that successfully described the dynamic behavior of the system and can be used in future control and optimization of the industrial process of capsular polysaccharide production.

Keywords: Bioreactors; Capsular polysaccharide production; Optimization.
\end{abstract}

\section{INTRODUCTION}

Bacterial meningitis is associated with high morbidity and mortality rates throughout the world. Therefore this disease is considered a serious worldwide public health problem. Neisseria meningitidis is one of the major pathogens that causes bacterial meningitis. Meningococci are divided into groups on the basis of their chemically and serologically distinct capsular polysaccharide. Five serogroups (A, B, C, Y and W135) can cause meningococcal disease, but approximately $90 \%$ of all cases are associated with serogroups A, B and C (Poolman, 1995).

Bivalent (A and C) and tetravalent (A, C, Y and W135) polysaccharide vaccines have been widely available since the early 1970s. Nevertheless, the use of purified polysaccharide vaccines has been limited due to their poor immunogenicity in infants and young children as well as the relatively short duration of immunity induced (Di Fabio, 1988; Frasch, 1990). Chemical conjugation of polysaccharides to protein carriers has been used to improve vaccines against meningoccocal disease. The resulting polysaccharide-protein conjugated vaccines are safe and immunogenic in young infants and induce long-term protection. Considerable progress has been made in the development of conjugate vaccines based on meningococcal group $\mathrm{C}$ polysaccharide (Leach et al., 1997; Ramsay et al., 2001).

In Brazil, polysaccharide vaccines against bacterial meningitis caused by Neisseria meningitidis

*To whom correspondence should be addressed 
serogroup $\mathrm{A}$ and $\mathrm{C}$ have been produced by BioManguinhos Institute (Fiocruz) since 1976 through a technology transfer agreement with the Mérieux Institute of France. Since then various modifications in the vaccine production sector have been made, aiming to adpt this process to Good Manufacture Practices rules.

Due to the importance of antimeningoccocal vaccines for national public health, strategies to optimize capsular polysaccharide production is an extremely significant goal for achieving high productivity in the manufacture of purified or conjugated polysaccharide vaccines. Thus, the use of engineering techniques such as mathematical modeling could be very important to design and implement alternative industrial strategies in order to improve the production of vaccines.

In this work, the process of capsular polysaccharide production by Neisseria meningitidis serogroup $\mathrm{C}$ was studied, aiming to obtain a mathematical model which could be used in future control and optimization in the industrial process.

\section{MATERIALS AND METHODS}

\section{Microorganism}

Neisseria meningitidis serogroup C 2135 strain, obtained from Mérieux Institute, France, was used in this study.

\section{Cultivation Medium}

Frantz medium (Frantz, 1942) composed of 1.6 $\mathrm{g} / \mathrm{L}$ of glutamic acid, $6.0 \mathrm{~g} / \mathrm{L}$ of $\mathrm{NaCl}, 2.5 \mathrm{~g} / \mathrm{L}$ fo $\mathrm{Na}_{2} \mathrm{HPO}_{4}, 1.25 \mathrm{~g} / \mathrm{L}$ of $\mathrm{NH}_{4} \mathrm{Cl}, 0.09 \mathrm{~g} / \mathrm{L}$ of $\mathrm{KCl}, 0.02$ $\mathrm{g} / \mathrm{L}, \quad \mathrm{MgSO}_{4} .7 \mathrm{H}_{2} \mathrm{O} \quad 0.12 \mathrm{~g} / \mathrm{L}$ of L-cysteine hydrochloride, $2.0 \mathrm{~g} / \mathrm{L}$ of yeast extract and $5.0 \mathrm{~g} / \mathrm{L}$ of glucose was prepared according to suggested procedures and was used in the flask and bioreactor submerged cultivation carried out in this study.

\section{Inoculation Procedure and Cultivation Conditions}

The bacterial strain was grown on Müller Hinton agar dishes at $37{ }^{\circ} \mathrm{C}$ during $16 \mathrm{~h}$ in a candle jar (5$10 \% \mathrm{CO}_{2}$ ) and harvested by washing with $2 \mathrm{~mL}$ sterile Frantz medium. The bacterial suspension was used to inoculate $50 \mathrm{~mL}$ of Frantz medium in 250 $\mathrm{mL}$ Erlenmeyer flasks, which were incubated at 37 ${ }^{\circ} \mathrm{C}$ under $200 \mathrm{rpm}$ in a shaker (New Brunswick Scientific Co, Edison, NJ, USA) for 4 hours. The content of the culture flasks was then inoculated in
$450 \mathrm{~mL}$ Frantz medium in $2 \mathrm{~L}$ Erlenmeyer flasks maintained under the previously described conditions. After this propagation procedure, growth suspension of $10 \%(\mathrm{v} / \mathrm{v})$ inoculum was used for experiments conducted in bioreactors.

\section{Bioreactor Experimental Conditions}

Experimental design runs were conducted in a set of four 1.0 L glass-vessel bioreactors (BIOSTAT Q, B. Braun Biotech International Diessel $\mathrm{GmbH}$, Germany) with a volume of $0.5 \mathrm{~L}$. Bioreactors were equipped with in situ sterilizable $\mathrm{pH}$ and polarographic dissolved oxygen electrodes, pt-100temperature sensors and magnetic stirring speed control. The fermentation conditions were controlled according to the experimental design schedule. Airflow rate was maintained at $0.8 \mathrm{~L} / \mathrm{min}$ with an upper aeration system. Temperature was maintained at $37^{\circ} \mathrm{C}, \mathrm{pH}$ was automatically controlled by $\mathrm{NaOH}$ $5 \mathrm{~N}$ at 7 and stirring speed was set to $1300 \mathrm{rpm}$. This stirring speed resulted in an equivalent volumetric oxygen transfer coefficient $\left(\mathrm{k}_{\mathrm{L}} \mathrm{a}\right)$ of $36 \mathrm{~h}^{-1}$.

\section{Analytical Assays}

Samples were collected from bioreactor culture broth and analytical assays for biomass, glucose and polysaccharide concentration were performed.

Optical density of the culture was measured at $600 \mathrm{~nm}$ using a Beckman DU-530 spectrophotometer. Dry cell weight (DCW) was determined by centrifuging $10 \mathrm{~mL}$ of culture broth at $10000 \mathrm{x}$ g and $4^{\circ} \mathrm{C}$ for $45 \mathrm{~min}$. The supernatant was removed and the pellet was resuspended in $10 \mathrm{~mL}$ of distilled water. The solution was centrifuged as above and the supernatant discarded. The pellet was dried in preweighed aluminum pans until constant weight was achieved $\left(80^{\circ} \mathrm{C}\right.$ for $\left.72 \mathrm{~h}\right)$ and the mass of the cell pellet was determined. DCW was demonstrated to be a linear function of optical density for $0.0<\mathrm{OD}_{600}<0.8$.

Polysaccharide concentration was obtained through quantification of the amount of sialic acid by the HCl-resorcinol colorimetric method (Svennerholm, 1957). The monomer concentration was determined by centrifuging $10 \mathrm{~mL}$ of culture broth at $10000 \mathrm{x} \mathrm{g}$ and $4^{\circ} \mathrm{C}$ for $20 \mathrm{~min}$ to remove cells. The supernatant was filtered with $0.22 \mu$ membranes (GSWP 04700 - Milipore Co, USA) and dialyzed with distilled water in 12 to $14 \mathrm{KDa}$ dialysis tubes (VWR Scientific Co, USA) at $4^{\circ} \mathrm{C}$ for 24 hours to remove interfering substances.

Glucose concentration was determined using the GOD/POD enzymatic method (Bayer Co., USA). 


\section{RESULTS AND DISCUSSION}

Aiming to develop a mathematical model that described the behavior of Neisseria meningitidis serogroup $\mathrm{C}$ in capsular polysaccharide production in bioreactors, experimental runs were conducted in one-liter glass vessels with $0.5 \mathrm{~L}$ of Frantz cultivation medium. Initial glucose concentration was varied from 5 to $13.5 \mathrm{~g} / \mathrm{L}$. Samples of the cultivation medium were collected at pre-established time intervals and analytical assays were conducted to obtain microbial growth, glucose uptake and polysaccharide time profiles.

Firstly, an analysis of the kinetics of capsular polysaccharide production by Neisseria meningitidis serogroup $\mathrm{C}$ was conducted. Based on microorganism behavior and transient characteristics common to processes operated in batch operation mode, such as variations in glucose concentration, accumulation of metabolic products and availability of dissolved oxygen, a set of modeling hypotheses was formulated.

In regard to microbial growth it was observed that the growth rate was highly dependent on oxygen concentration in the cultivation medium. Two different regions were delimited according to availability of dissolved oxygen and the results show that the specific microbial growth rate was directly proportional to the concentration of dissolved oxygen in the cultivation medium. Microbial growth was limited by concentration of glucose. Nevertheles no growth substrate inhibition effects were observed in the glucose concentration range studied in this work.

Glucose consumption also seems to be affected by the availability of dissolved oxygen. At the beginning of cultivation, when oxygen concentration was higher, the rate of glucose uptake was shown to be much lower than the highest specific microbial growth rates attained in this stage. On the other hand, when oxygen concentration tended to values near zero, an increase in glucose uptake could be observed in the complete range of initial substrate concentration tested. This behavior could be associated with a distinguished glucose metabolism by Neisseria meningitidis according to higher or lower availability of oxygen (Fu et al., 1995 oxygen).

Accumulation of capsular polysaccharide accumulation occurred in two different ways: in part it was growth-associated, i.e., the number of capsules increased due to the appearance of new cells and in part it was associated with the accumulation of polysaccharide on the surface of existing cells. The effect of dissolved oxygen was once more observed. Limited availability of oxygen favored the specific polysaccharide production, i.e., accumulation of capsules per bacterial unit. Even after microbial growth stopped, production of the capsules continued. Nevertheless, the hypothesis of the existence of a maximum quantity of surface polysaccharide per bacterial unit was suggested. Since capsular polysaccharide is not systematically discarded as some bacterial exopolysaccharides, an excessive accumulation of this structure on the bacterial surface may hinder interactions between cells and their surroundings and consequently there may be a maximum quantity of this structure per bacterial unit.

Based on the assumed hypothesis, a mathematical model was developed for the process of capsular polysaccharide production by Neisseria meningitidis C. Equations 1 to 4 show the structure of this model, which is respectively composed of cell, glucose, polysaccharide and oxygen mass balance.

$$
\begin{aligned}
& \frac{\mathrm{dX}}{\mathrm{dt}}=\left(\mu_{\mathrm{X}}-\mu_{D}\right) X \\
& \frac{\mathrm{dS}}{\mathrm{dt}}=-\left(\sigma_{\mathrm{A}}+\sigma_{\mathrm{M}}\right) \mathrm{X} \\
& \frac{\mathrm{dP}}{\mathrm{dt}}=\left(\pi_{1}+\pi_{2}\right) \mathrm{X} \\
& \frac{\mathrm{dpO}}{\mathrm{dt}}=\mathrm{k}_{\mathrm{L}} \mathrm{a}\left(100-\mathrm{pO}_{2}\right)-\phi X
\end{aligned}
$$

where $\mathrm{X}, \mathrm{S}$ and $\mathrm{P}$ are cell concentration $(\mathrm{g} / \mathrm{L})$, glucose concentration $(\mathrm{g} / \mathrm{L})$ and capsular polysaccharide concentration $(\mathrm{mg} / \mathrm{L}) ; \mathrm{pO}_{2}$ is the percentage of oxygen saturation; $\mu_{\mathrm{X}}$ and $\mu_{\mathrm{D}}$ are respectively biomass growth and death specific rates; $\sigma_{\mathrm{A}}$ and $\sigma_{\mathrm{M}}$ are respectively specific rate of glucose uptake under conditions of at higher and lower availability of oxygen; $\pi_{1}$ is the specific rate of growth associated with polysaccharide formation and $\pi_{2}$ is the specific rate of accumulation of capsular polysaccharide per bacterial unit; $\mathrm{k}_{\mathrm{L}} \mathrm{a}$ is the global oxygen transfer coefficient and $\phi$ is the specific rate of oxygen consumption. In Table 1 the kinetic expressions which compose the structure of the proposed phenomenological model are shown.

Equations 5 to 13 are functions that mathematically describe all the phenomenological characteristics formerly analyzed which compose the set of model hypotheses formulated through the 
experimental observation of the kinetics of capsular polysaccharide production by Neisseria menigitidis C. The model parameters were estimated using a computational routine based on the simplex method of parameter estimation, which minimizes the sum of squares of the difference between predicted and experimental values of biomass, glucose, polysaccharide and concentration of dissolved oxygen. The estimated values for phenomenological model parameters are presented in Table 2 .

Table 1: Kinetic Equations of the Phenomenological Model

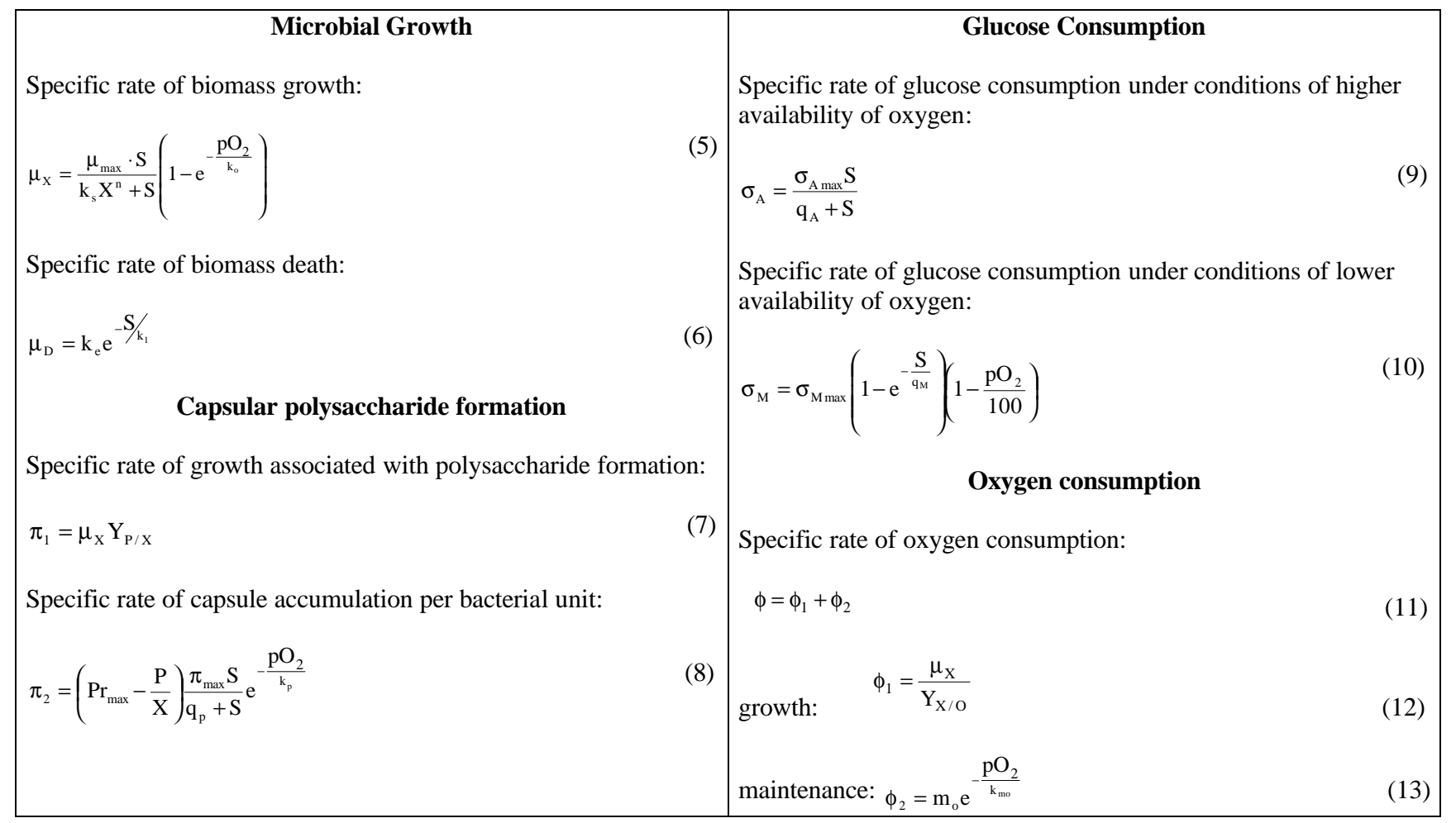

Table 2: Estimated Values for Phenomenological Model Parameters

\begin{tabular}{|l|l|l|l|}
\hline Microbial growth & Glucose consumption & Product formation & Oxygen consumption \\
\hline$\mu_{\max }=0.677 \mathrm{~h}^{-1}$ & $\sigma_{\mathrm{Amax}}=0.294 \mathrm{~h}^{-1}$ & $\mathrm{Y}_{\mathrm{P} / \mathrm{X}}=28.7 \mathrm{mg} / \mathrm{g}$ & $\mathrm{k}_{\mathrm{L}} \mathrm{a}=35.13 \mathrm{~h}^{-1}$ \\
$\mathrm{k}_{\mathrm{S}}=0.0318(\mathrm{~g} / \mathrm{L})^{-0.82}$ & $\mathrm{q}_{\mathrm{A}}=0.912 \mathrm{~g} / \mathrm{L}$ & $\operatorname{Pr}_{\max }=102.7 \mathrm{mg} / \mathrm{g}$ & $\mathrm{Y}_{\mathrm{X} / \mathrm{O}}=1.46 \cdot 10^{-4}(\mathrm{~g} / \mathrm{L}) /(\%)$ \\
$\mathrm{k}_{\mathrm{o}}=0.646 \%$ & $\sigma_{\mathrm{Mmax}}=0.849 \mathrm{~h}^{-1}$ & $\pi_{\max }=0.245 \mathrm{~h}^{-1}$ & $\mathrm{~m}_{\mathrm{O}}=2006(\%) /(\mathrm{g} / \mathrm{Lh})$ \\
$\mathrm{k}_{\mathrm{e}}=0.0778 \mathrm{~h}^{-1}$ & $\mathrm{q}_{\mathrm{M}}=3.22 \mathrm{~g} / \mathrm{L}$ & $\mathrm{q}_{\mathrm{p}}=0.0143 \mathrm{~g} / \mathrm{L}$ & $\mathrm{k}_{\mathrm{mo}}=26.1 \%$ \\
$\mathrm{k}_{1}=1.173 \mathrm{~g} / \mathrm{L}$ & & $\mathrm{k}_{\mathrm{p}}=2.84 \%$ & \\
$\mathrm{n}=1.8$ & & & \\
\hline
\end{tabular}

In Figures 1 to 5 the results for predictions met by the proposed mathematical model are presented. As can be seen, the model was capable of predicting the experimental phenomena previously observed in a satisfactory manner. Results show that proposed functions successfully described the kinetics of capsular polysaccharide production by $N$. meningitidis $\mathrm{C}$.

Figure 1 shows that the proposed model predicted the fall in the specific rate of microbial growth following the decrease in availability of dissolved oxygen. Glucose uptake for this system was also well described by the mathematical model, which successfully predicted both the reduced rate of glucose consumption in region of the maximum oxygen concentration region and the increased consumption under conditions of limited availability of oxygen. 


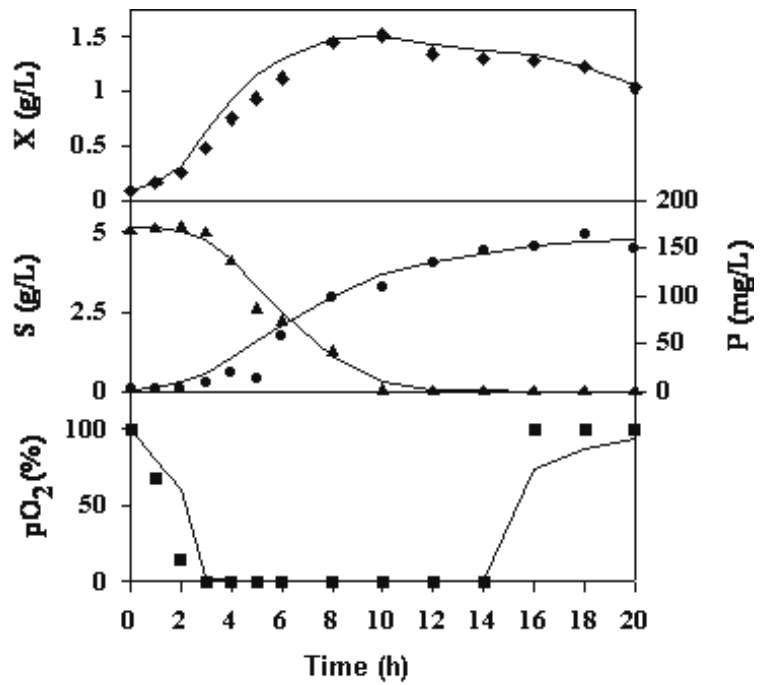

Figure 1: Mathematical Model Prediction (-) for Experimental Time Profiles for Biomass ( $v$ ), Glucose $(\sigma)$, Polysaccharide $(\lambda)$ and $\mathrm{pO}_{2}(v)$. Batch Run with $\mathrm{S}_{0}=5 \mathrm{~g} / \mathrm{L}$

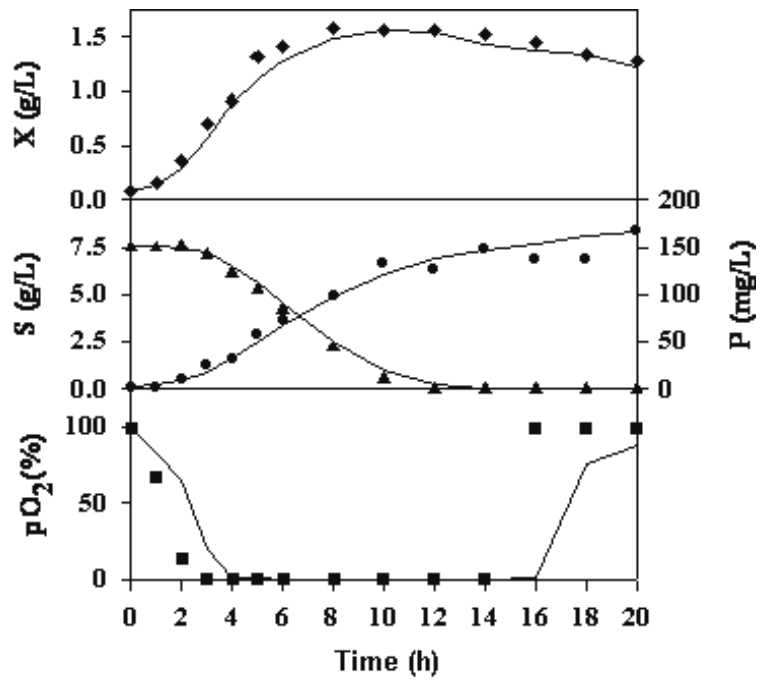

Figure 2: Mathematical Model Prediction (-) for Experimental Time Profiles for Biomass (v), Glucose $(\sigma)$, Polysaccharide $(\lambda)$ and $\mathrm{pO}_{2}(v)$. Batch Run with $\mathrm{S}_{0}=7.5 \mathrm{~g} / \mathrm{L}$

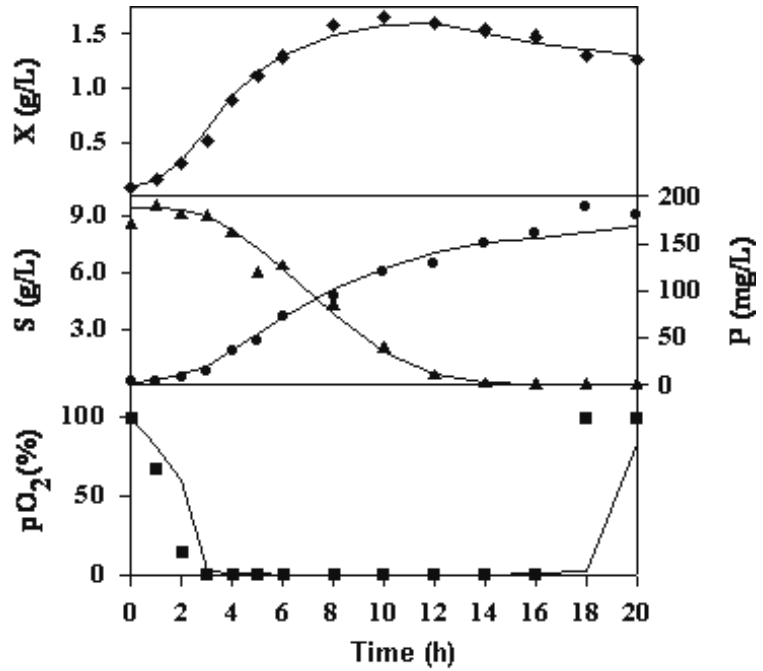

Figure 3: Mathematical Model Prediction (-) for Experimental Time Profiles for Biomass (v), Glucose $(\sigma)$, Polysaccharide $(\lambda)$ and $\mathrm{pO}_{2}(v)$. Batch Run with $\mathrm{S}_{0}=9 \mathrm{~g} / \mathrm{L}$ 


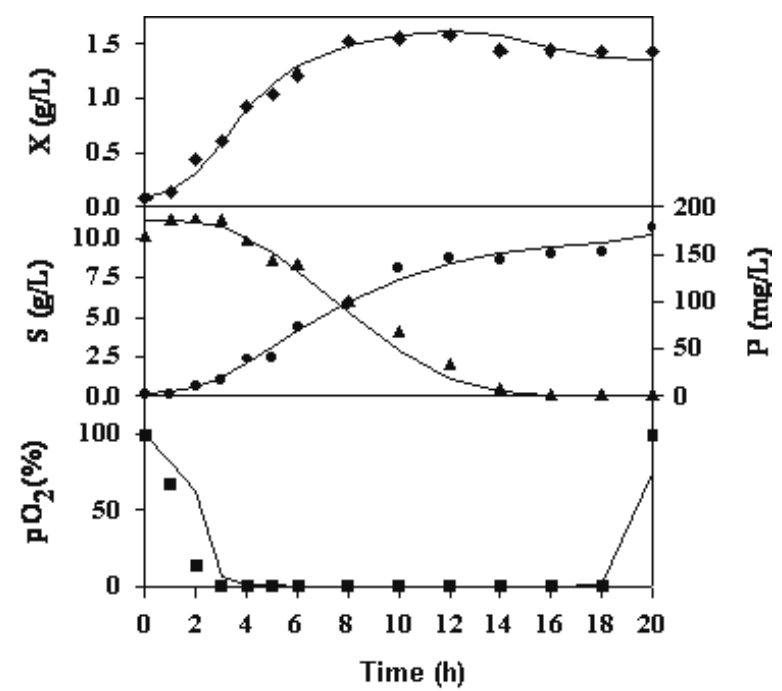

Figure 4: Mathematical Model Prediction (-) for Experimental Time Profiles for Biomass ( $v$ ), Glucose $(\sigma)$, Polysaccharide $(\lambda)$ and $\mathrm{pO}_{2}(v)$. Batch Run with $\mathrm{S}_{0}=11 \mathrm{~g} / \mathrm{L}$

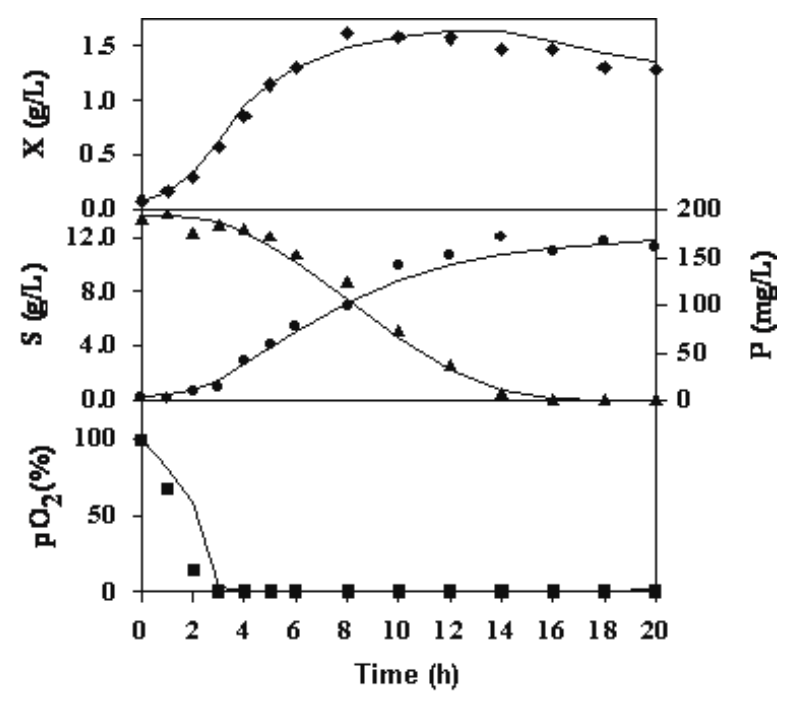

Figure 5: Mathematical Model Prediction (-) for Experimental Time Profiles for Biomass (v), Glucose $(\sigma)$, Polysaccharide $(\lambda)$ and $\mathrm{pO}_{2}(v)$. Batch Run with $\mathrm{S}_{0}=13.5 \mathrm{~g} / \mathrm{L}$

Figures 4 and 5 contain the results for batch runs conducted with initial glucose concentrations greater than $10 \mathrm{~g} / \mathrm{L}$. As can be seen, the model developed described the limited accumulation of polysaccharide due to the lack of new bacteria cell formation. The model prediction indicated that although the glucose was completely consumed, there was no significant difference in the final concentration of polysaccharide between the batch runs. Since final concentrations of biomass were very similar for both experimental runs, this could be explained by one o the model assumptions, which assumed that there was a maximum number of capsules per bacterial unit.

The mathematical model based on equations for biomass, glucose, capsular polysacharide and dissolved oxygen mass balance successfully predicted the dynamic behavior of capsular polysaccharide production by Neisseria meningitidis $\mathrm{C}$ in the entire experimental range studied in this work. Therefore, the proposed model could be employed as an efficient tool for simulation and implementation of future control and optimization schemes for this process of vaccine production.

\section{CONCLUSIONS}

In this work, the process of capsular polysaccharide production by Neisseria meningitis sorogrupo $\mathrm{C}$ in bioreactors was studied. Based on experimental observations from five batch runs 
conducted in one-liter bioreactors, a mathematical model which describes the kinetics of the process was obtained.

Experimental results showed that the availability of dissolved oxygen in the cultivation medium somewhat determined kinetics of the microorganisms. Conditions of higher concentration of oxygen favored microbial growth. However a decrease in the specific capsular polysaccharide production in this region of maximum microbial growth was observed. This could be related to the use of a common lipid intermediate, either in the construction of cell walls - an essential structure for bacterial survival - or in the biosynthesis of capsular polysaccharide (Masson and Holbein, 1985). On the other hand, the faster accumulation of capsules under conditions of low concentration of dissolved oxygen could also be associated with the need to produce this cell protection structure in situations of stress, such as limited availability of oxygen (Weiser et al., 2001). Glucose uptake also seems to be affected by oxygen concentration. In fact, this affect could be related to different carbohydrate metabolisms according to higher or lower availability of oxygen (Fu et al., 1995).

Solutions provided by the mathematical model structure, i.e., the set of functions that describe the specific rates of microbial growth, glucose uptake and polysaccharide formation was formulated through a phenomenological analysis of the microorganism transient behavior according to oxygen availability in the cultivation medium.

The mathematical model solutions were shown to be in agreement with experimental data since the model was capable of efficiently describing the system dynamics under the entire range of experimental conditions. Therefore, the model developed can be employed in the searching for and implementation of strategies of process control and optimization that aim at maximizing industrial polysaccharide vaccine production.

\section{NOMENCLATURE}

$\begin{array}{ll}\mathrm{k}_{1} & \text { parameter in Equation 6 } \\ \mathrm{k}_{\mathrm{e}} & \text { parameter in Equation 6 } \\ \mathrm{k}_{\mathrm{L}} \mathrm{a} & \begin{array}{l}\text { global oxygen transfer } \\ \text { coefficient }\end{array} \\ \mathrm{k}_{\mathrm{mo}} & \text { parameter in Equation 13 } \\ \mathrm{k}_{\mathrm{o}} & \text { parameter in Equation 5 } \\ \mathrm{k}_{\mathrm{p}} & \text { parameter in Equation 8 } \\ \mathrm{k}_{\mathrm{s}} & \text { parameter in Equation } 5\end{array}$

$(\mathrm{g} / \mathrm{L})^{-0.82}$
$\mathrm{m}_{\mathrm{O}} \quad$ parameter in Equation 13

$\mathrm{n} \quad$ parameter in Equation 5

$\mathrm{S}$ concentration of glucose

P concentration of capsular polysaccharide

$\mathrm{pO}_{2} \quad$ percentage of oxygen saturation

$\mathrm{Pr}_{\max } \quad$ parameter in Equation 8

$\mathrm{q}_{\mathrm{A}} \quad$ parameter in Equation 9

$\mathrm{q}_{\mathrm{M}} \quad$ parameter in Equation 10

$\mathrm{q}_{\mathrm{p}} \quad$ parameter in Equation 8

$\mathrm{X}$ concentration of biomass

$\mathrm{Y}_{\mathrm{P} / \mathrm{X}} \quad$ parameter in Equation 7

$\mathrm{Y}_{\mathrm{X} / \mathrm{O}} \quad$ parameter in Equation 12

$\phi \quad$ specific rate of oxygen consumption.

$\mu_{\mathrm{D}} \quad$ specific rate of biomass death

$\mu_{\max } \quad$ parameter in Equation 5

$\mu_{\mathrm{X}} \quad$ specific rate of biomass growth

$\pi_{1} \quad$ specific rate of growthassociated polysaccharide formation

$\pi_{2} \quad$ specific rate of accumulation of capsular polysaccharide per bacterial unit

$\pi_{\max } \quad$ parameter in Equation 8

$\sigma_{\mathrm{A}} \quad$ specific rate of glucose uptake at higher availability of oxygen

$\sigma_{\text {Amax }} \quad$ parameter in Equation 9

$\sigma_{M} \quad$ specific rate of glucose uptake at lower availability of oxygen

$\sigma_{\mathrm{Mmax}}$ parameter in Equation 10
$(\%) /(\mathrm{g} / \mathrm{Lh})$

$(\mathrm{mg} / \mathrm{L})$

$(\mathrm{mg} / \mathrm{g})$

$(\mathrm{mg} / \mathrm{g})$

$(\mathrm{g} / \mathrm{L}) /(\%)$

$\left(\mathrm{h}^{-1}\right)$

\section{REFERENCES}

Di Fabio, J.L., Polisacáridos Capsulares como Vacunas Antibacterianas, Adel. Microbiol. Enf. Infecc., vol.7, no.1, pp. 1-17 (1988).

Frantz, I.D., Growth Requirements of Meningococcus, J. Bact., vol.43 no.6, pp. 757-761 (1942).

Frasch, C.E., Production and Control of Neisseria meningitidis Vaccines. In: Advances in Biotechnological Processes. vol.13 - Bacterial Vaccines. Edited by Avshalom Mizrahi, New York, John Wiley \& Sons, Inc. (1990).
Fu, J., Bailey, J., King, J.J., Parker, C.B. et al., Recent Advances in the Large Scale Fermentation 
of Neisseria meningitidis Group B for the Production of an Outer Membrane Protein Complex, Biotechnol., vol.13, pp. 170-174 (1995).

Leach, A., Twumasi, P.A., Kumah, S., Banya, W.S., et al., Induction of Immunologic Memory in Gambian Children by Vaccination in Infancy with Group A Plus Group C Meningococcal Polysaccharide-Protein Conjugate Vaccine,. J. Infect. Dis., vol.175, pp. 200-204 (1997).

Masson, L., Holbein, B.E., Role of Lipid Intermediate(s) in the Synthesis of Serogroup B Neisseria meningitidis Capsular Polysaccharide, Journal of Bacteriol., vol. 161, no.3, pp. 861-867 (1985).

Poolman, J.T., Development of a Meningococcal Vaccine, Infectious Agents and Disease, vol.4, pp. 13-28 (1995).

Ramsay, M.E., Andrews, N., Kaczmarski, E.B., Miller, E., Efficacy of Meningococcal Serogroup C Conjugate Vaccine in Teenagers and Toddlers in England, Lancet, vol.357, no.9251, pp. 195196 (2001).

Svennerholm, L., Quantitative Estimation of Sialic Acids. II. A Colorimetric ResorcinolHydrochloric Acid Method, Biochimica et Biophysica Acta, vol.24, pp. 604-611 (1957).

Weiser, J.N., Bae, D., Epino, H., Gordon, S.B. et al., Changes in Availability of Oxygen Accentuate Differences in Capsular Polysaccharide Expression by Phenotypic Variants and Clinical Isolates of Streptococcus pneumoniae, Infection and Imunity, vol.69, no.9, pp. 5430-5439 (2001). 